\title{
AN AXISYMMETRIC BENDING ANALYSIS OF FUNCTIONALLY \\ GRADED ANNULAR PLATE UNDER TRANSVERSE LOAD VIA GENERALIZED DIFFERENTIAL QUADRATURE METHOD
}

\author{
Hamad M.H' ${ }^{1}$ F. Tarlochan ${ }^{2}$ \\ Center for Innovation and Design, Universiti TenagaNasional, Kajang, Malaysia
}

\begin{abstract}
An axisymmetric bending analysis of four-parameter functionally graded annular plate under uniform transverse load is studied. Generalization of four-parameter power-law distribution presented in literature is proposed. Four kinds of material profiles through the functionally graded annular plate thickness are illustrated by varying the four parameters of power-law distribution. Generalized differential quadrature (GDQ) method is used to discretize the system of governing equations. The convergence of the method is illustrated and the validation of the results is done by a comparison with another study which available in the literature and good agreement between two studies was found.
\end{abstract}

Index Terms:axisymmetric, four-parameter power-law distribution, annular plate, symmetric, asymmetric, functionally graded plate

\section{INTRODUCTION}

Annular plates in structural components play a major role in engineering applications. Related to this area is the bending deformation of these types of plates which is notably crucial in their design ranging from automotive railway brake systems to disks which constitute vital components particularly in turbo machines.

Functionally graded materials (FGMs) were first introduced in 1984 [1] whereby a number of researchers became interested to study them. FGMs are newly introduced class of composite materials derived from a number of different phases of material constituents (ceramic and metal). These different microstructure phases of FGMs depict different functions. Generally, the FGMs obtain the multi structural status based on their property gradation which involves the process of gradually varying the volume fraction of constituent materials. Subsequently, their material properties depict a change which is soft and continuous from one surface to the other. With this, interface problems are eradicated as a result of the sudden change of the material properties [2, 3].

Most research concerning FGMs annular plates have focused on analyzing bending, buckling and vibration whereby the material profile distribution is taken into consideration looking at the thickness of the annular plate. In this case, a simple power law distribution is utilized as discussed in the literature.
Reddy et al. [4] study relates to axisymmetric bending of functionally graded circular and annular plates whereby the first order shear deformation plate theory was used. Ma and Wang [5] analyzed further by discussing the relationship between axisymmetric bending and buckling solutions of FGM circular plates. Third-order plate theory and classical plate theory were demonstrated and discussed in detail in their study. In addition, asymmetric flexural vibration and an additional stability analysis of FGM circular plates was included in thermal environment by using finite element technique was presented by Prakash and Ganapathi [6]. Also, three-dimensional free vibration of functionally graded annular plates whereby boundary conditions were different using Chebyshev-Ritz method was also studied by Dong [7]. Malekzadeh et al. [8] also showed how in thermal environment in-plane free vibration analysis of FGM thin-to-moderately thick deep circular arches. Third-order shear deformation theory was used by Saidi et al. [9] to analyze axisymmetric bending and buckling of thick functionally graded circular plates. Subsequently, fourth-order shear deformation theory was researched by Sahraee and Saidi [10] to study axisymmetric bending of thick functionally graded circular plates.

Besides this, Sepahi et al. [11] analyzed the effects of big deflection of thermo-mechanical loaded annular FGM plates on nonlinear elastic foundation using the differential quadrature method. Geometrically nonlinear post-buckling of an imperfect circular FGM plate was studied by Li et al. [12] who found both mechanical load and transverse non-uniform temperature rise. A 
study conducted by Malekzadeh et al. [13] resulted in threedimensional free vibration of thick functionally graded annular plate in thermal environment by differential quadrature technique. An investigation of nonlinear analysis of functionally graded circular plates was conducted by Nosier and Fallah [14]. It was related to asymmetric transverse loading, according to the first-order shear deformation plate theory based on von Karman non-linearity.

In addition, Sburlati and Bardella [15] studied threedimensional elasticity solution of functionally graded thick circular plates. Correspondingly, Golmakani and Kadkhodayan [16] studied axisymmetric nonlinear bending analysis of annular functionally graded plate. The study used third-order shear deformation theory. A precise closed form answer for free vibration of circular and annular moderately thick functionally graded plates of first-order shear deformation theory was studied by Hosseini-hashemi et al. [17] Nie and Zhong's study [18] was on frequency analysis of multi-directional functionally graded annular plates using state space differential quadrature method. It was based on three-dimensional theory of elasticity. It must be noted that direct displacement method was conducted by Yan et al. [19] with the aim to represent the axisymmetric bending of FG circular plates under transverse loads that were arbitrary. Another theory using Mindlin's plate theory about free vibration was investigated by Ebrahimi et al [20]. This study was concerned about moderately thick shear deformable annular functionally graded by plate.

The effects of coupling between in-plane and out-of-plane vibrating modes of smart functionally graded circular/annular plates was examined by Hashemi et al. [21]. Alipour and Shariyat [22] through an elasticity-equilibrium-based zigzag theory for axisymmetric bending was examined. Their research included stress analysis of FG circular sandwich plate whereby a Maclaurin-type sense solution was applied. An analysis of buckling circular plates of FGMs under uniform radial compression was investigated by Najafizadeh and Eslami [23]. Nonlinear bending and post-buckling of a functionally graded circular plate was examined by Ma and Wang [24] whereby the conditions were mechanical and thermal loading.

A variety of material profiles via the functionally graded annular plate thickness can be depicted utilizing a generalization of the power- law distribution. It would seem that the advantage of using generalized power-law distribution is the possibility of investigating the influence of the differing kinds of material profiles comprising symmetric, asymmetric and classic on mechanical characteristics of a structure. Currently, some researchers utilized four-parameter power-law distribution to examine the influence of the structure's parameters of mechanical behavior. A four-parameter power-law distribution was employed by Tornabene [25] for the purpose of studying free vibration of functionally graded conical, cylindrical shell and annular plate structures with the use of first-order shear deformation theory. Vibration of four-parameter of moderately thick FGM parabolic panels and shells of revolution was examined by Tornabene and Viola [26] and it utilized first-order shear deformation theory. Also, a three-dimensional analysis of thermal stresses based on four-parameter continuous grading fiber reinforced cylindrical panels was studied by Aragh and Yas [27]. Yas and Aragh [28] came up with an elasticity solution as their study presented free vibration of fourparameter FG fiber orientation cylindrical panels with the adoption of differential quadrature method.

Based on the elastic analysis of ceramic-metal graded annular plate, there seems to be no study on the analysis of axisymmetric bending in annular plates using four-parameter power-law distribution in the open literature to the best of the researcher's knowledge. It must be stressed that the benefit of using generalized power-law distribution is for the illustration and presentation of results arising from symmetric, asymmetric and classic profiles that will be a significant contribution to the area of study. Indeed, there is a need to conduct this study as past studies in this area have been lacking particularly the technical literature about the influence of the power law exponent, of the power law distribution choice and of the selection of the four parameters on the axisymmetric bending behavior of FG annular plate.

This study is aimed filling this apparent gap in studies in this area by providing the axisymmetric bending analysis results for annular plate with generalized power-law distribution. In order to meet the aims, four different four-parameter power-law distributions, including symmetric, two asymmetric and classic profiles are used. From the thickness of the annular plate, material profiles are depicted by varying the four-parameters of power-law distributions. Moreover, in this study symmetric, asymmetric and classic volume fraction profiles are illustrated for the purpose of investigating the behavior of axisymmetric bending of annular plate. As special case of the general distribution laws, classical volume fraction profiles can be obtained.

\section{MATHEMATICAL FORMULATION}

Consider a FG annular plate with thickness $\mathrm{h}$ axisymmetricwith respect to z-axis, inner radius $b$, and outer radius a asshown in Figure 1, and it is subjected to uniform pressure qz. The midplane of the plate is referred to the cylindrical coordinate system $(\mathrm{r}, \mathrm{\Theta}, \mathrm{z})$ in the radial and circumferential and axial directions respectively. 


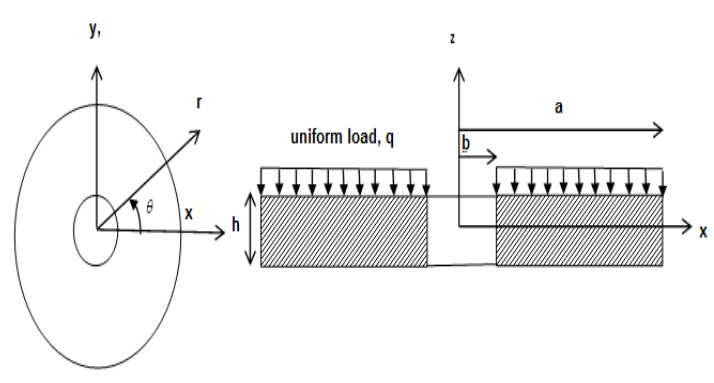

Figure 1:Annular disk configuration with load distribution

Typically, the FGMs are made of a mixture of two constituents. In this research, it is assumed that the FGMs are made of a mixture of ceramic and metal constituents. The material properties of the FG plate vary continuously and smoothly in thickness direction $\mathrm{z}$ and are functions of volume fraction of constituent materials:

$$
\mathrm{P}(\mathrm{z})=\left(\mathrm{p}_{\mathrm{c}}-\mathrm{p}_{\mathrm{m}}\right) \mathrm{V}_{\mathrm{c}}+\mathrm{p}_{\mathrm{m}}
$$

Where $\mathrm{P}(\mathrm{z})$ : material property at location $\mathrm{z}$ through thickness. In this paper, the ceramic volume fraction $\mathrm{Vc}$ follows fourparameter power-law distribution:

$\mathrm{V}_{c}=\left(1-\mathrm{a}(0.5-\mathrm{z} / \mathrm{h})+\mathrm{b}(0.5-\mathrm{z} / \mathrm{h})^{c}\right)^{p}$

Where $\mathrm{p}$ : volume fraction index $(0 \leq p \leq \infty)$

$a, b, c$ : parameters dictate the material variation profile of the FG annular plate thickness.

As the volume fraction index is equal to zero $(\mathrm{p}=0)$ or equal to infinity $(p=\infty)$, the homogeneous isotropic material is obtained as a special case of functionally graded material. Indeed, from Equation (2) it is possible to obtain

$\mathrm{p}=0 \rightarrow \mathrm{Vc}=1, \mathrm{Vm}=0 \rightarrow \mathrm{P}(\mathrm{z})=\mathrm{pc}$

$\mathrm{p}=\infty \rightarrow \mathrm{Vc}=0, \mathrm{Vm}=1 \rightarrow \mathrm{P}(\mathrm{z})=\mathrm{pm}$

Some material profiles through the FG plate thickness are illustrated in Figures 2 - 5. In Figure 2, the classical volume fraction profile presented as special case of the general distribution law (Equation 2) by setting $a=1, b=0$. As can be seen from Figure 2, for the distribution $V c(a=1 / b=0, p)$ the material composition is continuously varied such that the top surface $(\mathrm{z} / \mathrm{h}=0.5)$ of the plate is ceramic rich, whereas the bottom surface $(\mathrm{z} / \mathrm{h}=-0.5)$ is metal rich. With another choice of the parameters a, b, c, it is possible to obtain symmetric and asymmetric volume fraction profiles as shown in Figures 3 and
4. In Figure 3, by setting $\mathrm{a}=1, \mathrm{~b}=1$ and $\mathrm{c}=2$ the distribution $\mathrm{Vc}(\mathrm{a}=1, \mathrm{~b}=1, \mathrm{c}=2, \mathrm{p})$ by varying the volume fraction index $\mathrm{p}$ and is symmetric respect to the reference surface $(\mathrm{z} / \mathrm{h}=0)$ of the plate. This distribution is characterized by the fact that both the top $(\mathrm{z} / \mathrm{h}=0.5)$ and bottom surface $(\mathrm{z} / \mathrm{h}=-0.5)$ are ceramic rich, while there is a mixture of two constituents through the thickness.

Figure 4 , shows asymmetric profile by setting $a=1, b=1$ and $c$ $=5$ in $\mathrm{Vc}(\mathrm{a}=1, \mathrm{~b}=1, \mathrm{c}=5, \mathrm{p})$. As shown from this figure, we have the same constituent at top and bottom surface, but the profile not symmetric respect to the reference surface $(\mathrm{z} / \mathrm{h}=0)$ of the plate. Figure 5 presents other case obtained by varying the parameters $a, b, c$. This profile is characterized that the top surface of the plate is ceramic rich, while the bottom surface shows a mixture of two constituents. Thus, as from this point of view, the aim of this research is to propose a generalization of the power-law distribution presented in literature and to study the influence of the power-law exponent and of the choice of the type of material profile on the mechanical behavior of annular structure considered.

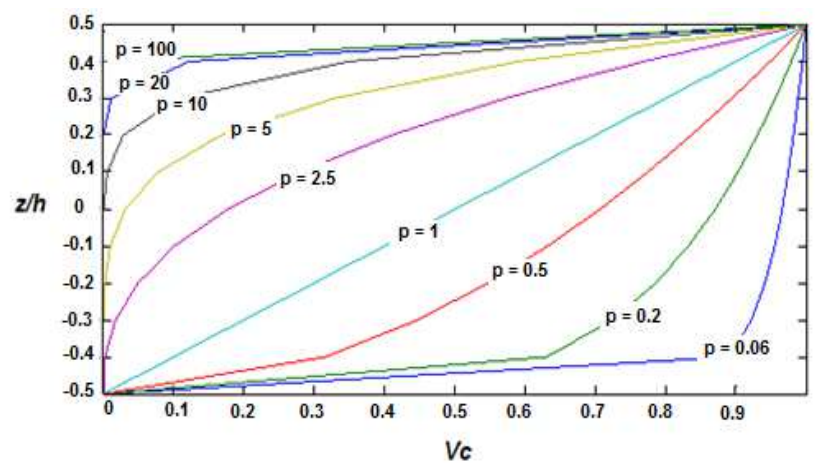

Figure 2: Variation of the ceramic volume fraction $\mathrm{Vc}$ through the thickness for different values of the power-law index $\mathrm{p}(\mathrm{a}=$ $1, \mathrm{~b}=0, \mathrm{c}=1, \mathrm{p})$.

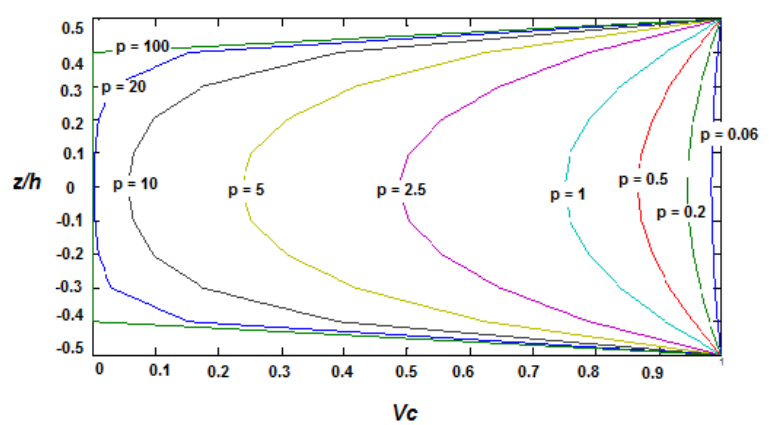

Figure 3: Variation of the ceramic volume fraction $\mathrm{Vc}$ through the thickness for different values of the power-law index $p(a=$ $1, b=1, c=2, p)$ 


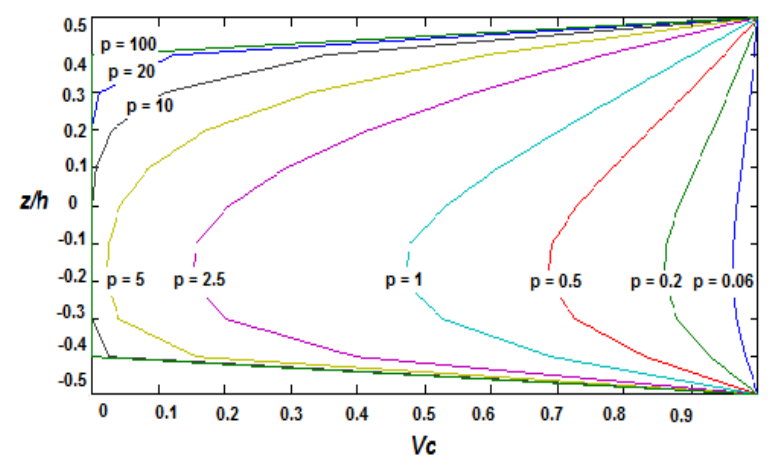

Figure 4:Variation of the ceramic volume fraction $\mathrm{Vc}$ through the thickness for different values of the power-law index $\mathrm{p}(\mathrm{a}=$ $1, \mathrm{~b}=1, \mathrm{c}=5, \mathrm{p})$.

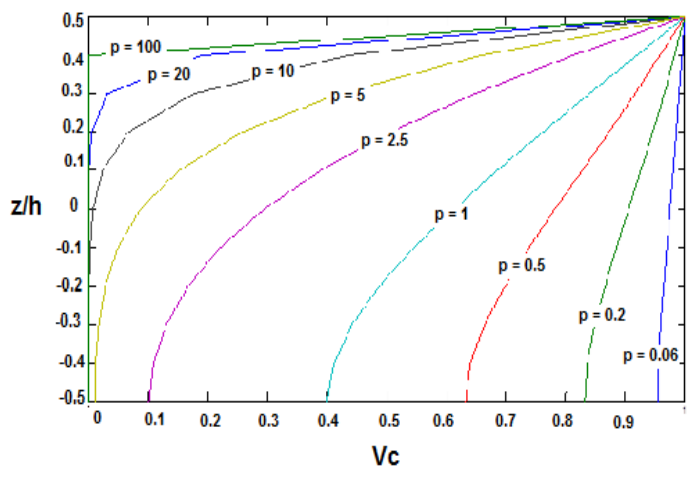

Figure 5: Variations of the ceramic volume fraction $\mathrm{Vc}$ through the thickness for different values of the power-law index p ( $\mathrm{a}=$ $0.8, b=0.2, c=5, p)$.

Base on the first-order shear deformation theory, displacement field in the cylindrical coordinate system can be written as:

$U(r, \theta, z)=z \varphi(r)$

$W(r, \theta, z)=w(r)$

Where $\varphi(r)$ represents the small transverse normal rotation about the $\square$ _axis and w(r) displacement at the mid-plane of the plate in the $\mathrm{z}$-direction

Strain-displacement relations

$\varepsilon_{\mathrm{r}}=\mathrm{z} \frac{\mathrm{d} \varphi}{\mathrm{dr}} \quad \varepsilon_{\theta}=\mathrm{z} \frac{\varphi}{\mathrm{r}}$

$\gamma_{\mathrm{rz}}=\varphi+\frac{\mathrm{dw}}{\mathrm{dr}}$
Stress-strain relations:

$$
\left\{\begin{array}{c}
\sigma_{\mathrm{r}} \\
\sigma_{\theta} \\
\tau_{\mathrm{rz}}
\end{array}\right\}=\left[\begin{array}{ccc}
\mathrm{Q}_{11} & \mathrm{Q}_{12} & 0 \\
\mathrm{Q}_{12} & \mathrm{Q}_{22} & 0 \\
0 & 0 & \mathrm{Q}_{66}
\end{array}\right]\left\{\begin{array}{c}
\varepsilon_{\mathrm{r}} \\
\varepsilon_{\theta} \\
\gamma_{\mathrm{rz}}
\end{array}\right\}
$$

Where

$$
\begin{aligned}
& Q_{11}=Q_{22}=(E(z)) /\left(1-v^{2}\right) \\
& \mathrm{Q}_{12}=v \mathrm{Q}_{11} \\
& \mathrm{Q}_{66}=\frac{E(z)}{2(1+v)}
\end{aligned}
$$

The total potential energy of the plate

$$
\begin{aligned}
& \Pi=U+V_{\mathrm{f}} \\
& \mathrm{U}=\frac{1}{2} \int\left[\sigma_{\mathrm{r}} \varepsilon_{\mathrm{r}}+\sigma_{\theta} \varepsilon_{\theta}+\tau_{\mathrm{rz}} \gamma_{\mathrm{rz}}\right] \mathrm{dv} \\
& \mathrm{V}_{\mathrm{f}}=\int(-\mathrm{qw}) \mathrm{dA}(6 \mathrm{c})
\end{aligned}
$$

Where, $\Pi, \mathrm{U}$ and $\mathrm{Vf}$ are the total potential energy, strain energy and the potential energy of the applied pressure loadThe resultant moments and the transverse force of the stresses are defined by:

$$
\begin{aligned}
& \left(\mathrm{M}_{\mathrm{r}}, \mathrm{M}_{\theta}\right)=\int_{-\mathrm{h} / 2}^{\mathrm{h} / 2}\left(\sigma_{\mathrm{r}}, \sigma_{\theta}\right) \mathrm{zdz} \\
& \mathrm{Q}_{\mathrm{r}}=\int_{-\mathrm{h} / 2}^{\mathrm{h} / 2} \tau_{\mathrm{rz}} \mathrm{dz}
\end{aligned}
$$

From equations $(4,5,7,8)$

$$
M_{r}=D_{11} \frac{d \varphi}{d r}+D_{12} \frac{\varphi}{r}
$$

$\mathrm{M}_{\theta}=\mathrm{D}_{12} \frac{\mathrm{d} \varphi}{\mathrm{dr}}+\mathrm{D}_{11} \frac{\varphi}{\mathrm{r}}$

$\mathrm{Q}_{\mathrm{r}}=\mathrm{k}_{\mathrm{s}} \mathrm{A}_{11}\left(\varphi+\frac{\mathrm{dw}}{\mathrm{dr}}\right)$

Where 
$\mathrm{D}_{11}=\int_{-\mathrm{h} / 2}^{\mathrm{h} / 2} \frac{\mathrm{E}(\mathrm{z})}{\left(1-\mathrm{v}^{2}\right)} \mathrm{z}^{2} d z$

$A_{11}=\int_{-h / 2}^{h / 2} \frac{E(z)}{2(1+v)} d z$

$\mathrm{ks}=5 / 6$ is the shear correction factor

Based on the Hamilton's principle

$\delta \varphi:$

$-\frac{\mathrm{d}}{\mathrm{dr}}\left(\mathrm{rM}_{\mathrm{r}}\right)+\mathrm{M}_{\theta}+\mathrm{rQ}_{\mathrm{r}}=0$

$\delta \mathrm{w}:$

$-\frac{\mathrm{d}}{\mathrm{dr}}\left(\mathrm{rQ}_{\mathrm{r}}\right)-\mathrm{qr}=0$

Equilibrium equation in terms of displacements

$D_{11} \frac{d^{2} \varphi}{d^{2}}+D_{11} \frac{1}{r} \frac{d \varphi}{d r}-D_{11} \frac{1}{r^{2}} \varphi-k_{s} A_{11}\left(\varphi+\frac{d w}{d r}\right)=0$

$\mathrm{k}_{\mathrm{s}} \mathrm{A}_{11}\left[\frac{\mathrm{d}^{2} \mathrm{w}}{\mathrm{dr}^{2}}+\frac{1}{\mathrm{r}} \frac{\mathrm{dw}}{\mathrm{dr}}+\frac{\mathrm{d} \varphi}{\mathrm{dr}}+\frac{1}{\mathrm{r}} \varphi\right]+\mathrm{q}=0$

Using the following non-dimensional parameters:

$\mathrm{R}=\mathrm{r} / \mathrm{a}, \mathrm{W}=\mathrm{w} / \mathrm{h}, \phi=\varphi, \delta=h / a, \beta=\mathrm{b} / \mathrm{a} \quad \lambda=\frac{\mathrm{A}_{11} \mathrm{a}^{2}}{\mathrm{D}_{11}}$
$\mathrm{R}^{2} \frac{\mathrm{d}^{2} \phi}{\mathrm{dR}^{2}}+\mathrm{R} \frac{\mathrm{d} \phi}{\mathrm{dR}}-\left(1+\mathrm{k}_{\mathrm{s}} \lambda \mathrm{R}^{2}\right) \phi-\mathrm{k}_{\mathrm{s}} \lambda \delta \mathrm{R}^{2} \frac{\mathrm{dW}}{\mathrm{dR}}=0$
$\lambda \delta \mathrm{R}^{2} \frac{\mathrm{d}^{2} \mathrm{~W}}{\mathrm{dR}^{2}}+\mathrm{k}_{\mathrm{s}} \lambda \delta \mathrm{R} \frac{\mathrm{dW}}{\mathrm{dR}}+\mathrm{k}_{\mathrm{s}} \lambda \mathrm{R}^{2} \frac{\mathrm{d} \phi}{\mathrm{dR}}+\mathrm{k}_{\mathrm{s}} \lambda \mathrm{R} \phi=-\frac{\mathrm{a}^{3} \mathrm{R}^{2} \mathrm{q}}{\mathrm{D}_{11}}$

Two boundary conditions are considered at each end of the annular plate as:

(1) Clamped-clamped (C-C):

$\mathrm{W}={ }^{\phi}=0$ at the two ends of the plate

(2) Clamped- free (C-F):

$$
\begin{aligned}
& \mathrm{W}=\phi=0 \text { at } \mathrm{r}=\mathrm{b} \\
& \mathrm{Mr}=\mathrm{Qr}=0 \text { at } \mathrm{r}=\mathrm{a}
\end{aligned}
$$

The generalized differential quadrature (GDQ) method is adopted to solve the differential equations of the annular plate. The core of the GDQ method is that the derivative of a function in a domain $(0 \leq x \leq L)$ is approximated as a weighted linear summation of a function values at all discrete points in that domain. Thus, GDQ method changes the governing differential equations into a set of corresponding simultaneous equations. To demonstrate the GDQ method, consider the r-th derivative of a function $\mathrm{f}(\mathrm{x})$ can be estimated as:

$$
\left(\delta f^{r}(x)\right) /\left.\left(\delta x^{r}\right)\right|_{X i}=\sum_{k=1}^{n} D_{i k}^{r} f\left(x_{k}\right) \quad i=1,2, . ., n
$$

Where xi are the discrete points in the variable domain, $\mathrm{D}_{\mathrm{ik}}^{(r)}$, and $f(x k)$ are the weighting coefficient and the function value at the discrete points.

Thus, for the first-order derivatives, the weighting coefficients can be calculated as [27]

$\mathrm{D}_{\mathrm{ik}}^{(1)}=\frac{\phi\left(\mathrm{x}_{\mathrm{i}}\right)}{\left(\mathrm{x}_{\mathrm{i}}-\mathrm{x}_{\mathrm{k}}\right) \phi\left(\mathrm{x}_{\mathrm{k}}\right)} \mathrm{i}, \mathrm{k}=1,2 \ldots \mathrm{n}, \mathrm{i} \neq \mathrm{k}$

Where, $\quad \phi\left(\mathrm{x}_{\mathrm{i}}\right)=\prod_{\mathrm{i}=1}^{\mathrm{n}}\left(\mathrm{x}_{\mathrm{i}}-\mathrm{x}_{\mathrm{k}}\right)$ i, $\mathrm{k}=1,2 \ldots \mathrm{n}, \mathrm{i} \neq \mathrm{k}$

After that, the domain of the annular plate is divided into $n$ grade points in $r$ direction. Chebyshev polynomial is the best method to evaluate the grid points in the domain of the plate [27]:

$r_{i}=b+\frac{a-b}{2}\left[1-\cos \left(\frac{i-1}{n-1} \pi\right)\right]_{i=1,2 \ldots n}$

The governing Equations (16) and (17) can be discretized according to the GDQ method as follows:

$\mathrm{R}_{\mathrm{i}}^{2} \sum_{\mathrm{k}=1}^{\mathrm{n}} \mathrm{D}_{\mathrm{ik}}^{(2)} \phi_{\mathrm{k}}+\mathrm{R}_{\mathrm{i}} \sum_{\mathrm{k}=1}^{\mathrm{n}} \mathrm{D}_{\mathrm{ik}}^{(1)} \phi_{\mathrm{k}}-\left(1+\mathrm{k}_{\mathrm{s}} \lambda \mathrm{R}_{\mathrm{i}}^{2}\right) \phi_{\mathrm{i}}-\mathrm{k}_{\mathrm{s}} \lambda \delta \mathrm{R}_{\mathrm{i}}^{2} \sum_{\mathrm{k}=1}^{\mathrm{n}} \mathrm{D}_{\mathrm{ik}}^{(1)} \mathrm{w}_{\mathrm{k}}=0$

$\mathrm{k}_{\mathrm{s}} \lambda \delta \mathrm{R}_{\mathrm{i}}^{2} \sum_{\mathrm{k}=1}^{\mathrm{n}} \mathrm{D}_{\mathrm{ik}}^{(2)} \mathrm{w}_{\mathrm{k}}+\mathrm{k}_{\mathrm{s}} \lambda \delta \mathrm{R}_{\mathrm{i}} \sum_{\mathrm{k}=1}^{\mathrm{n}} \mathrm{D}_{\mathrm{ik}}^{(1)} \mathrm{w}_{\mathrm{k}}+$

$\mathrm{k}_{\mathrm{s}} \lambda \mathrm{R}_{\mathrm{i}}^{2} \sum_{\mathrm{k}=1}^{\mathrm{n}} \mathrm{D}_{\mathrm{ik}}^{(1)} \phi_{\mathrm{k}}+\mathrm{k}_{\mathrm{s}} \lambda \mathrm{R}_{\mathrm{i}} \phi_{\mathrm{i}}=-\frac{\mathrm{a}^{3} \mathrm{R}_{\mathrm{i}}^{2} \mathrm{q}}{\mathrm{D}_{11}}$

Where $\mathrm{i}=2, \ldots, \mathrm{n} . \mathrm{D}_{\mathrm{ik}}^{(r)}$ is the weighting coefficient for the nth order derivatives of $\mathrm{w} \& \phi$. The boundary conditions can be discretized by the GDQ as: 
(1) clamped-clamped

$$
\begin{array}{ll}
\mathrm{W} 1=\phi_{1}=0 & \text { at } \mathrm{r}=\mathrm{b} \\
\mathrm{Wn}=\phi_{n}=0 & \text { at } \mathrm{r}=\mathrm{a}
\end{array}
$$

(2) clamped-free

$$
\begin{aligned}
& \mathrm{W} 1=\phi_{1}=0 \\
& \sum_{k=1}^{n} D_{n k}^{(1)} \phi_{k}+v \phi_{n}=0 \quad \mathrm{k}_{\mathrm{s}} \lambda \delta \sum_{\mathrm{k}=1}^{\mathrm{n}} \mathrm{D}_{\mathrm{ik}}^{(1)} \mathrm{W}_{\mathrm{k}}+\mathrm{k}_{\mathrm{s}} \lambda \phi_{\mathrm{n}}=0 \\
& \text { at } \mathrm{r}=\mathrm{a}
\end{aligned}
$$

The congregation of the governing equations and the related boundary conditions lead to a set of simultaneous linear algebraic equation which can be write in matrix form as:

$$
\left[\begin{array}{ll}
\mathrm{k}_{\mathrm{bb}} & \mathrm{k}_{\mathrm{bd}} \\
\mathrm{k}_{\mathrm{db}} & \mathrm{k}_{\mathrm{dd}}
\end{array}\right]\left\{\begin{array}{l}
\left(\Delta_{\mathrm{b}}\right) \\
\left(\Delta_{\mathrm{d}}\right)
\end{array}\right\}=\left\{\begin{array}{l}
(0) \\
(\mathrm{q})
\end{array}\right\}
$$

Where $k_{b b}$ and $k_{b d}$ are the stiffness matrices of boundary of the boundary conditions and the size of it are $4 \times 4$ and $4 \times 2(n-2)$ respectively.

$k_{d b}$ and $k_{d d}$ are stiffness matrices of governing equations and have size of $2(n-2) \times 4$ and $2(n-2) \times 2(n-2)$ respectively.

The vector $\Delta_{b}$ contains the displacements corresponds to the boundary points and is eliminated using the static condensation technique. The stiffness matrix in Equations 20 can be reduced into the form of

$\left[-\mathrm{k}_{\mathrm{db}} \mathrm{k}_{\mathrm{bb}}^{-1} \mathrm{k}_{\mathrm{bd}}+\mathrm{k}_{\mathrm{dd}}\right]\left\{\Delta_{\mathrm{d}}\right\}=\{\mathrm{q}\}$

From the above equation the vector of domain displacements $\Delta_{d}$ can be evaluated.

In order to examine the accuracy and efficiency of the results of this paper, we made a comparison with another study. To implement this, an axisymmetric bending of a clamped-clamped functionally graded circular plate under uniformly distributed load q. Metallic volume fraction power law distribution through plate thickness and all the material properties were obtained from Reddy et al. [3] as shown in Table 1. The evaluation of the comparisons between the present numerical analysis and Reddy's exact results are illustrated in Table 2 for nondimensional maximum deflection, $\mathrm{w}_{\max }=\frac{64 \mathrm{wD}_{\mathrm{c}}}{\mathrm{qa}^{4}}$ with $\mathrm{D}_{\mathrm{c}}=\frac{\mathrm{E}_{\mathrm{c}} \mathrm{h}^{3}}{12\left(1-\mathrm{v}^{2)}\right.}$.
Table 1:Mechanical properties of ceramic and metal of circular FGM plate [3]

\begin{tabular}{lcc}
\hline material & Young's modulus $(\mathrm{Gpa})$ & Poison's ratio, \\
\hline ceramic & 278.41 & 0.288 \\
metal & 110.25 & 0.288 \\
\hline
\end{tabular}

Table 2: Accuracy and efficiency of maximum deflection for clamped circular FG plate under uniform transverse distributed load q

\begin{tabular}{|c|c|c|}
\hline $\begin{array}{c}\text { Volume fraction } \\
\text { Index p }\end{array}$ & h/a = 0.2 & \multirow{2}{*}{ Reddy et al. [ 3 ] } \\
\cline { 2 - 3 } & present & 2.979 \\
$\mathbf{0}$ & 2.977 & 1.613 \\
$\mathbf{2}$ & 1.612 & 1.473 \\
$\mathbf{6}$ & 1.473 & 1.404 \\
$\mathbf{8}$ & 1.403 & 1.362 \\
$\mathbf{1 0}$ & 1.361 & 1.333 \\
$\mathbf{1 5}$ & 1.332 & 1.289 \\
$\mathbf{2 0}$ & 1.288 & 1.265 \\
$\mathbf{2 5}$ & 1.265 & 1.250 \\
$\mathbf{3 0}$ & 1.250 & 1.239 \\
$\mathbf{3 5}$ & 1.238 & 1.231 \\
$\mathbf{4 0}$ & 1.230 & 1.225 \\
$\mathbf{5 0}$ & 1.224 & 1.216 \\
$\mathbf{1 0 0}$ & 1.216 & 1.199 \\
& 1.198 & \\
\hline
\end{tabular}

Where $\mathrm{h}$ and a are the thickness and radius of the circular plate. The conclusion from these comparisons is an excellent agreement between these results.

After that, for investigating the convergence of the results of this research, consider the first boundary condition (clampedclamped) and the deflection is estimated by increasing the number of grid points from $n=5$ to $n=33$ as shown in Figure 6 . For this boundary condition, $\mathrm{n}=13$ is needed to get an accurate result for deflection. For another boundary condition (clampedfree), the result for the convergence of the deflection for this case is presented in Figure 7. From this figure the number of grid points begin with $n=11$ to $n=79$ as shown. It is noted that for $n=53$ is needed to get an accurate result for the deflection. 


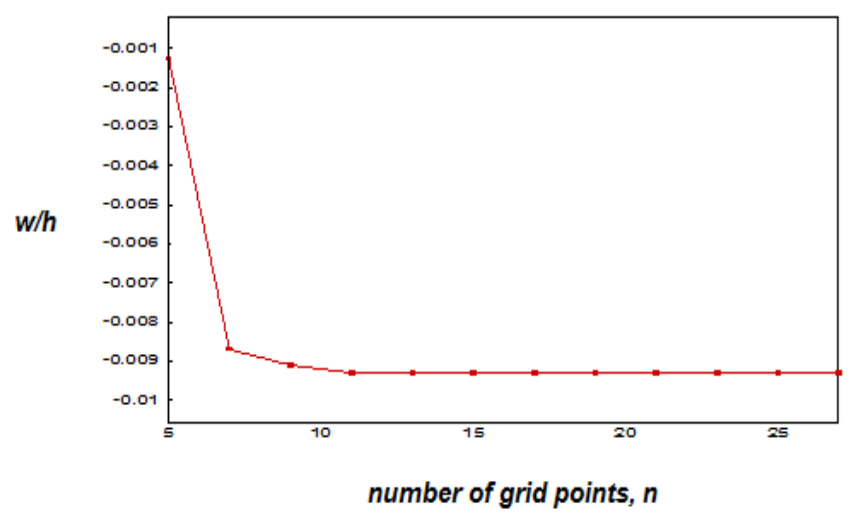

Figure 6:Convergence of the maximum normalized deflection $\mathrm{w} / \mathrm{h}$ with the number of grid points (horizontal axis) for (C-C) annular plate.

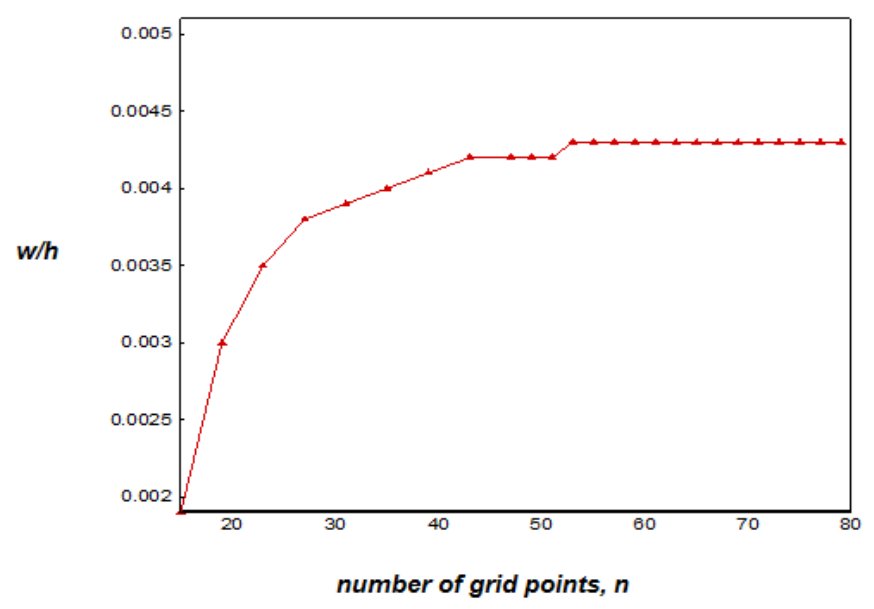

Figure 7:Convergence of the maximum normalized deflection $\mathrm{w} / \mathrm{h}$ with the number of grid points For $(\mathrm{C}-\mathrm{F})$ annular plate

\section{RESULTS AND DISCUSSION}

In order to demonstrate the effect of type material distribution through the thickness of FG annular plate by applying fourparameter power law distribution, four kinds of material distribution through the thickness of annular plate are investigated. Preposition the components of functionally graded materials consist of zirconia as ceramic and aluminum as metal. The mechanical properties of ceramic and metal are [26]:Ec = $168(\mathrm{GPa}), \mathrm{Em}=70(\mathrm{GPa}), \square \mathrm{c}=0.3$ and $\square \mathrm{m}=0.3$, where $\mathrm{Ec}$, $\mathrm{Em}, \square \mathrm{c}$ and $\square \mathrm{m}$ are Young's modulus and Poison's ratio for ceramic and metal respectively. The dimensions of the FG annular plate is: $\mathrm{h}=0.02 \mathrm{~m}, \mathrm{a}=0.1 \mathrm{~m}, \mathrm{~b}=0.01 \mathrm{~m}$, where $\mathrm{h}, \mathrm{a}$ and $b$ are thickness, outer radius and inner radius of annular plate respectively. Two types of boundary conditions are studied, clamped and clamped-free.
For clamped condition Figure 8 presents the non-dimensional deflection along the radius for symmetric material distribution with different values of volume fraction index $\mathrm{p}$. As it expected, the deflection values for full ceramic $\mathrm{p}=0$, are lesser than those for full metal $\mathrm{p}=100$, due to higher elasticity modulus of ceramic. Furthermore, it is observed that the deflection increases with the increasing the volume fraction index $\mathrm{p}$. Figures 9,10 and 11 illustrate the variation of deflection along the radius for asymmetric, (top surface is ceramic rich and bottom surface is metal rich) and classic material distribution through the thickness of the plate.

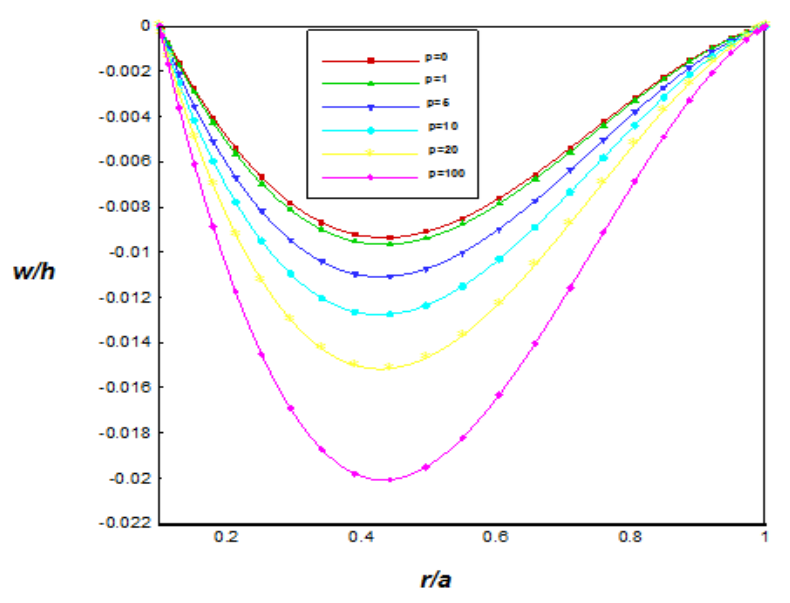

Figure 8:Bending response for symmetric material profile through thickness of clamped annular FGM plate under uniform transverse load for different values of $\mathrm{p}$.

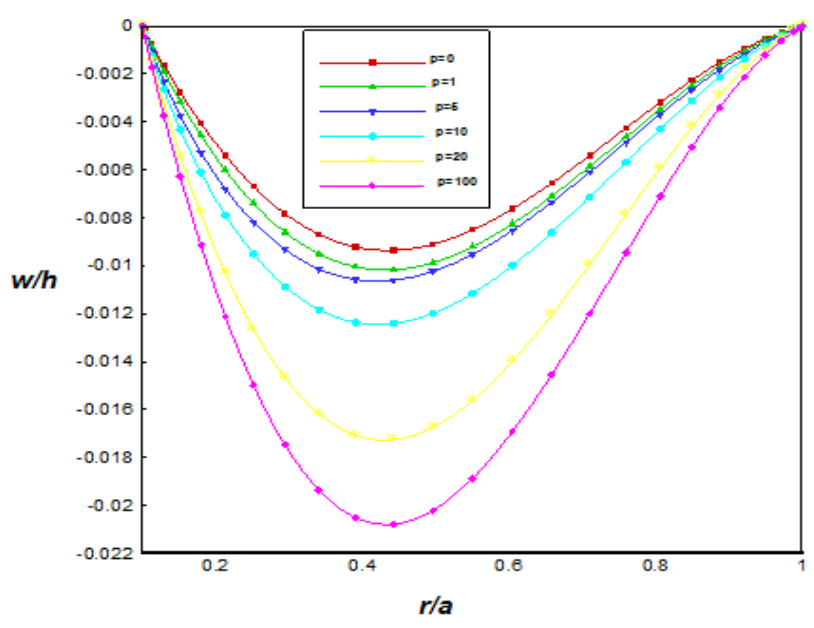

Figure 9:Bending response for axisymmetric material profile through thickness of clamped annular FGM plate under uniform transverse load for different values of $\mathrm{p}$.

\section{Clamped-Clamped condition}




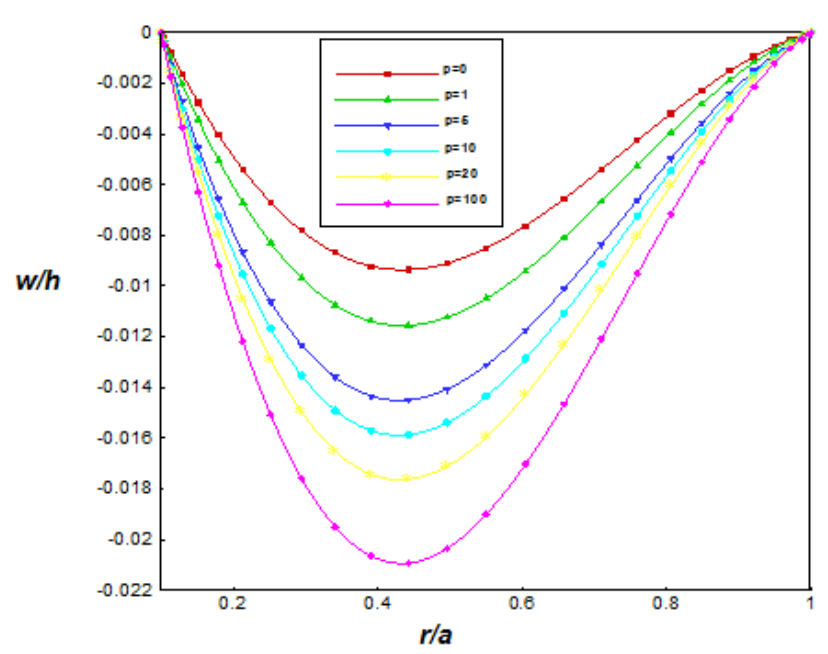

Figure10:Bending response for material profile (top surface ceramic and bottom surface mixed) of clamped annular FGM plate under uniform transverse load for different values of $\mathrm{p}$.

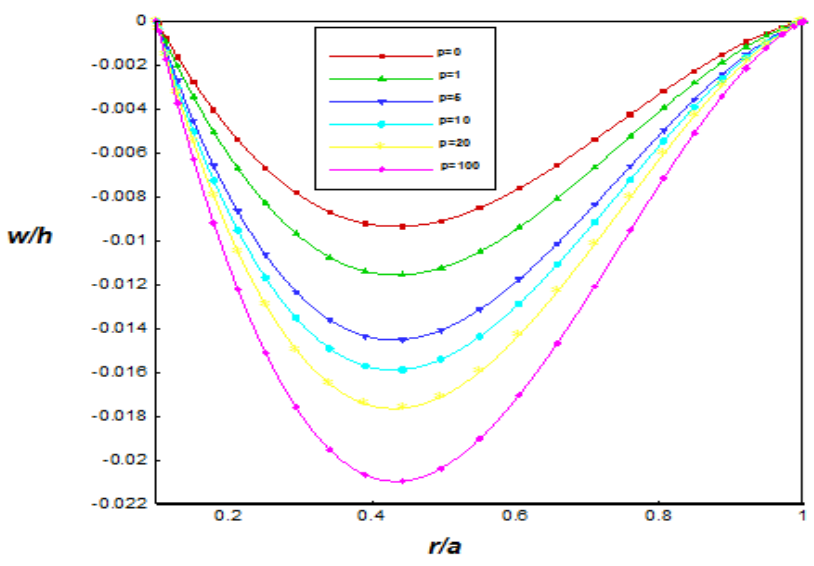

Figure 11:Bending response for classic material profile through thickness of clamped annular FGM plate under uniform transverse load for different values of $\mathrm{p}$.

Also, for these cases the deflection values increases with the increasing in the values of volume fraction index and reaches the maximum value at $\mathrm{R}(\mathrm{r} / \mathrm{a})=0.44$. Figure 12 shows the influence of the volume fraction index on the kind of the material distribution. At the end, Figure 13 demonstrates the deflection values along the radius of the annular plate for symmetric, asymmetric, (top surface is ceramic rich and bottom surface is metal rich) and classic material distribution through the thickness of the plate with volume fraction index $p=1$. From this figure, it is observed that the deflection for as a material distribution through the thickness of the annular plate is symmetric has lesser value than the values of deflection, as the material distribution asymmetric, (top surface is ceramic rich and bottom surface is metal rich) and classical material distribution

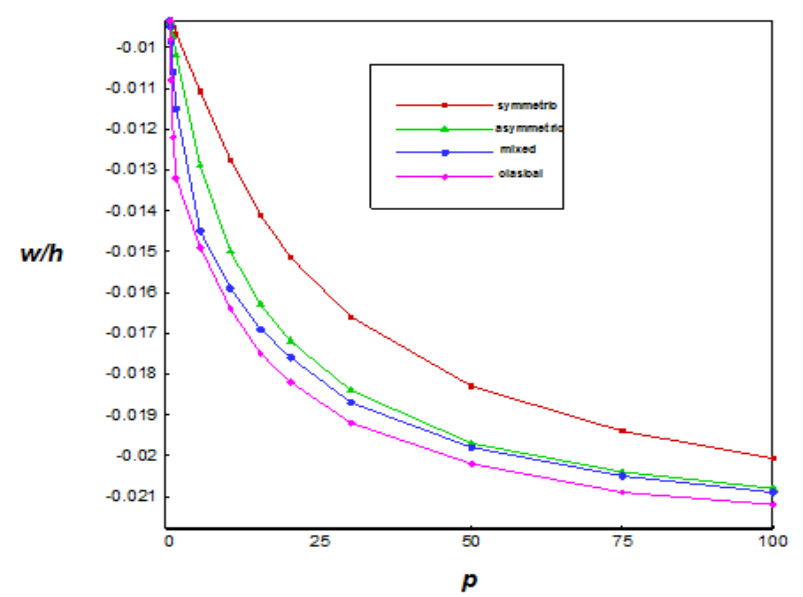

Figure 12:Effect of volume fraction index $p$ on the deflection of clamped annular FGM plate for different types of material profiles at $\mathrm{R}=0.44$

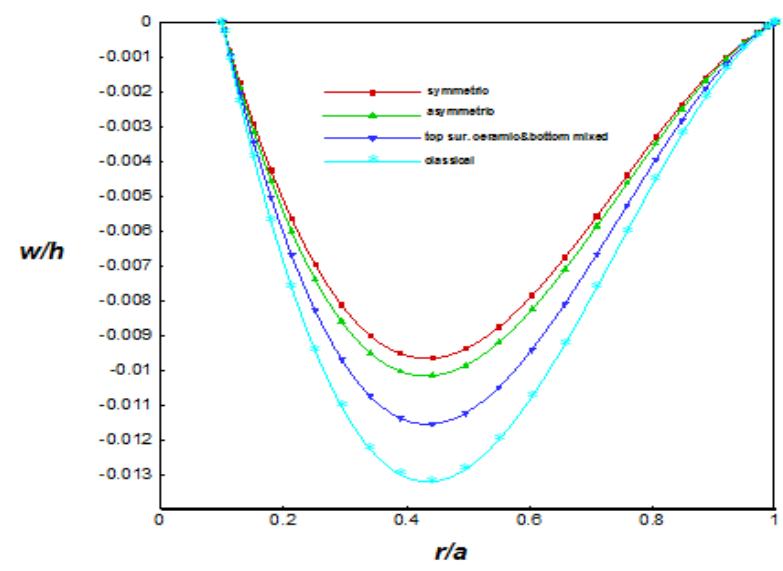

Figure 13:Bending response for different types of material profiles through thickness of clamped FGM plate at $p=1$

\section{Clamped-Free condition}

For clamped-free condition, Figure 14 shows the deflection along the radius of the annular plate with different values of volume fraction index, as the profile of material distribution through the thickness is symmetric. From this figure, it is observed that the maximum deflection is at $\mathrm{R}=1$ and it increases with the increasing in the volume fraction index. Figures 15, 16 and 17 show the variation of deflection along the radius for asymmetric, (top surface is ceramic rich and bottom surface is metal rich) and classic material distribution through the thickness of the plate. Also, for these cases the deflection values increases with the increasing in the values of volume fraction index. At the end, Figure 18 demonstrates the deflection values 
along the radius of the annular plate for symmetric, asymmetric, (top surface is ceramic rich and bottom surface is metal rich) and classic material distribution through the thickness of the plate with volume fraction index $p=1$. From this figure, it is observed that the deflection for as a material distribution through the thickness of the annular plate is symmetric has lesser value than the values of deflection, as the material distribution asymmetric, (top surface is ceramic rich and bottom surface is metal rich) and classical material distribution.

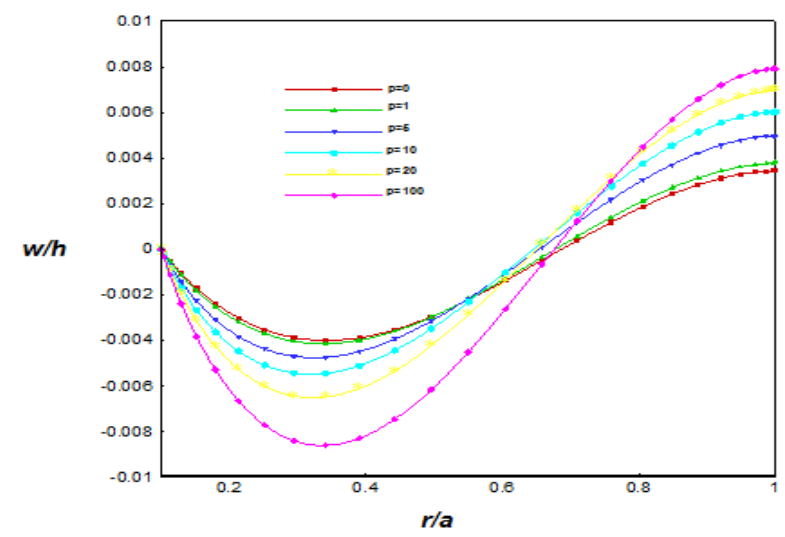

Figure14:Bending response of symmetric material profile through thickness of clamped-free annular FGM plate for different values of $\mathrm{p}$.

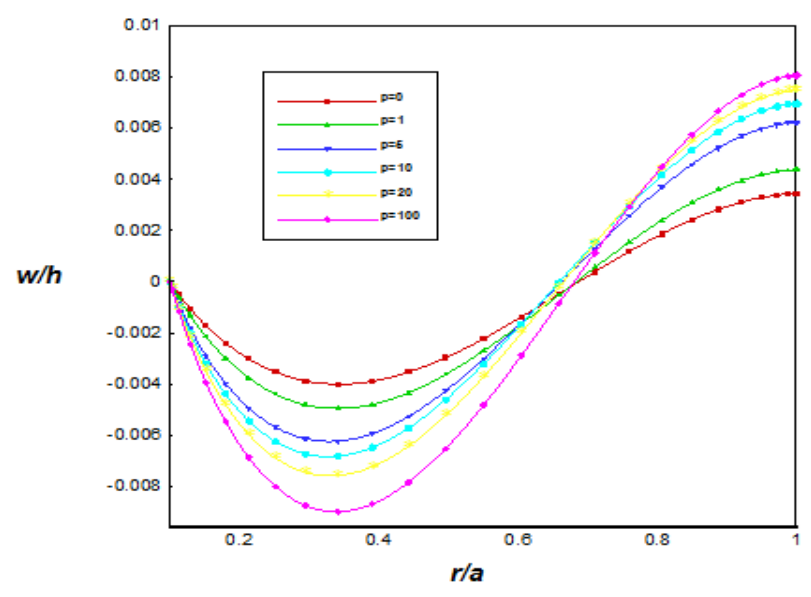

Figure 15:Bending response of material profile (top surface ceramic and bottom mixed) through thickness of clamped-free annular FGM plate under different values of $\mathrm{p}$.

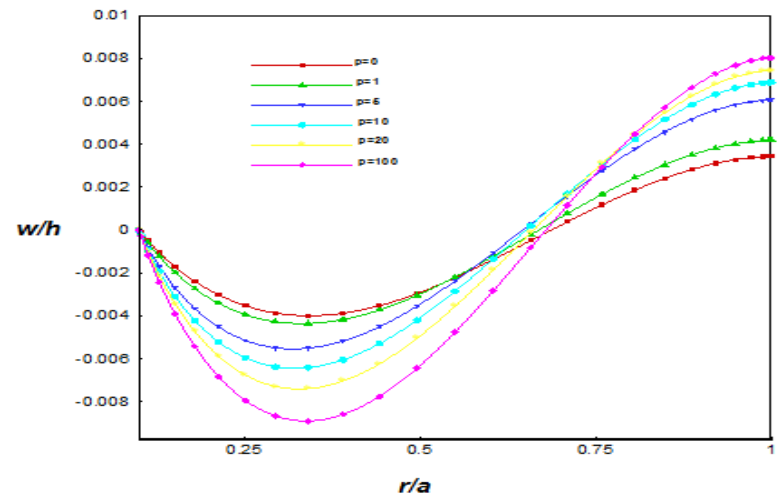

Figure 16:Bending response of asymmetric material profile through thickness of clamped-free annular FGM plate under different values of $\mathrm{p}$.

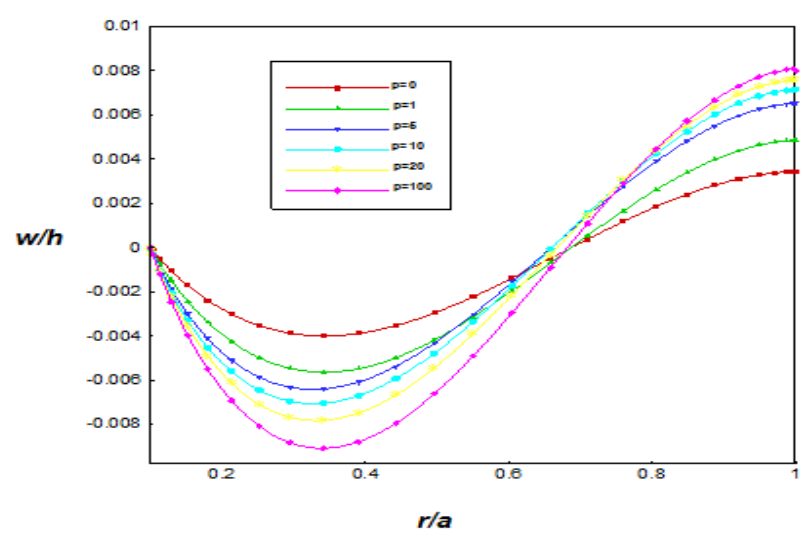

Figure 17:Bending response of classic material profile through thickness of clamped-free annular FGM plate for different values of $\mathrm{p}$.

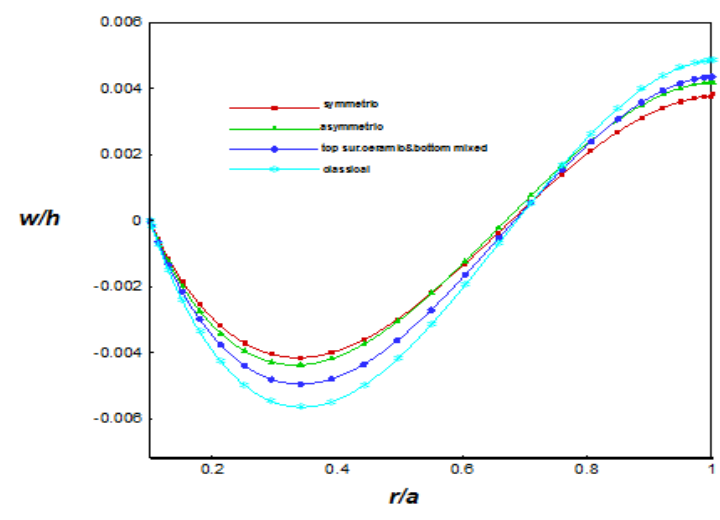

Figure 18:Bending response for different kinds of material profile through thickness of clamped-free annular FGM plate for $p=1$ 


\section{CONCLUSIONS}

An axisymmetric bending analysis of functionally graded annular plate under uniformly distributed load by generalized differential quadrature method is studied. The effect of the kind material profile on the deflection of FG annular plate when the profile of material distribution through thickness of the plate is symmetric, asymmetric, (top surface is ceramic rich and bottom surface is metal rich) and classic has a great influence on the value of deflection, where the symmetric profile is lesser value of deflection from the other types of profiles. Besides this, the value of deflection for all kinds of material profiles increases with the increasing in the value of the volume fraction index for two types of boundary conditions, clamped and clamped-free condition.

\section{REFERENCES}

[1] Koizumi, M. "The concept of FGM," in Ceramic Transactions, Functionally Gradient Materials, Vol. 34, eds. Holt, J. B., Koizumi, M., Hirai, T. and Munir, Z. A. (American Society, Westerville, Ohio), 3-10. 1993.

[2] M. Zaki, F. Tarlochan, S. Ramesh. Two Dimensional Elastic Deformations of Functionally Graded Coated Plates with Clamped Edges. Composite B: Engineering. 2012, 45, (1), pp. 1010-1022.

[3] Hui-ShenShen. Functionally Graded Materials: Nonlinear Analysis of Plates and Shells. Taylor \& Francis, 2010.

[4] Reddy, J.N., Wang, C.M. Axisymmetric bending of functionally graded circular and annular plates. European Journal of Mechanics A/Solids. 1999, 18: 185-199.

[5] Ma, L.S., Wang, T.S. Relationships between axisymmetric bending and buckling solutions of FGM circular plates based on third-order plate theory and classical plate theory. International Journal of Solids and Structures 2004, 41: 85-101.

[6] Prakesh Y, Genepethi M. Axisymmetric flexural vibration and thermoelastic stability of functionally graded material circular plate using finite element method. Compos Part B: Engineering 2008, 371:49014910.

[7] Dong CI. Three dimensional free vibration analysis of FG annular plates using the Chebyshev-Ritz method. Material and Design 2008, 29: 1518-1525.

[8] Malekzadeh P, Atashi MM, Karami G. In-plane free vibration of FG circular arches with temperaturedependent properties under thermal environment. Journal Sound Vibration 2009, 326: 837-851.

[9] Saidi A.R, Rasouli A. ,Sahraee S. Axisymmetric bending and buckling analysis of FG circular plates using thirdorder shear deformation theory. Composite Structures. 2009, 89:110-119.

[10] Sahraee,S. , Saidi,A. R. Ax symmetric bending analysis of thick functionally graded circular plates using fourth- order shear deformation theory. European journal of mechanics A/solids 2009, 28: 974-984.

[11] Sepahi O., Forouzan M. R., Malekzadeh P. Large deflection analysis of thermo-mechanical loaded annular FGM plates on nonlinear elastic foundation via DQM. Composite Structures. 2010, 92: 2369-2378.

[12] Li S., Zhang J, Zhao Y. Nonlinear thermo mechanical post-buckling of circular functionally graded material plate with geometric imperfection. Thin-wall Structures. 2007; 45: 528-536.

[13] Malekzadeh P., Shahpari S.A., Ziaee H.R. Threedimensional free vibration of thick functionally graded annular plates in thermal environment. Journal of Sound and Vibration 2010; 329: 425-442.

[14] Nosier A., Fallah F. Nonlinear analysis of functionally graded circular plates under asymmetric transverse loading. International Journal of Non-Linear Mechanics 2009. 44: 928-942.

[15] Sburlati R, Bandella L. Three-dimensional elastic solutions for FG circular plates. European Journal of Mechanics A/Solids. 2011; 30: 219-235.

[16] Galmekane EM, Kedkhodeyan M. Axisymmetric nonlinear bending analysis of annular functionally graded plate using third-order shear deformation theory. Compos Structures. 2011; 93: 973-982.

[17] Hosseini-Hashemish, Fedaee M, Es'haghi M. An exact closed form solution for free vibration of circular and annular moderately thick functionally graded plates based on first-order shear deformation theory. International Journal of Mechanical Science 2010; 52: 1025-1035.

[18] Nie GJ, Zhong Z. Frequency analysis of multi-directional functionally graded annular plates by using state space differential quadrature method based on threedimensional theory of elasticity. Applied Math Model 2010; 34: 608-616.

[19] Yun W, Rongqiao, Haojiang D. Axisymmetric bending of FG circular plates under arbitrary transverse loads. Composite Structures 2010; 92: 1683-1693.

[20] Ebrahimi E, Rastgoo A, Atai AA. Free vibration of moderately thick shear deformable annular functionally graded plate by using Mindlin's plate theory. European Journal of Mechanics A/Solids 2009; 28: 962-973.

[21] HosseiniSh, Azimzadeh M, Rokni H. A 3-D Ritz solution for free vibration of circular/annular functionally graded plates integrated with piezoelectric layers. International Journal of Engineering Science 2010; 48:1971-1984.

[22] Alipour MM, Shariyat M. An elasticity-equilibriumbased zigzag theory for axisymmetric bending and stress analysis of the functionally graded circular sandwich plates, using a Maclaurin-type series solution. European Journal of Mechanics - A/Solids 2012; 34: 78-101.

[23] M.M. Najafizadeh, M.R. Eslami. Buckling analysis of circular plates of functionally graded materials under 
uniform radial compression, International Journal of Mechanical Sciences 2002. 44(12): 2479-2493

[24] LS Ma, TJ Wang. Nonlinear bending and post-buckling of a functionally graded circular plate under mechanical and thermal loadings. International Journal of Solids and Structures, 2003. 40 (13-14): 3311-3330

[25] F. Tornabene. Free vibration analysis of functionally graded conical, cylindrical shell and annular plate structures with a four-parameter power-law distribution. Computer Methods in Applied Mechanics and Engineering. 2009. 198 (37-40): 2911-2935.

[26] F. Tornabene, E. ViFree. Vibrations of four-parameter functionally graded parabolic panels and shells of revolution. European Journal of Mechanics - A/Solids 2009. 28(5): 991-1013

[27] M.H. Yas, B. SobhaniAragh. Elasticity solution for free vibration analysis of four-parameter functionally graded fiber orientation cylindrical panels using differential quadrature method. European Journal of Mechanics A/Solids 2011. 30 (5): 631-638

[28] B. SobhaniAragh, M.H. Yas. Effect of continuously grading fiber orientation face sheets on vibration of sandwich panels with FGM core. International Journal of Mechanical Sciences 2011. 53 (8): 628-638

\section{BIOGRAPHIES}

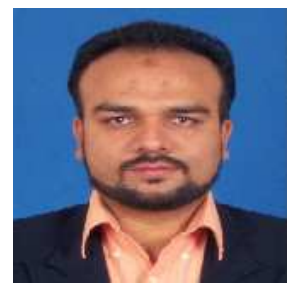

F. Tarlochanwas born in Malaysia. He obtained his Bachelors in Mechanical Engineering and Masters in Biomedical Engineering from Purdue University, USA. His $\mathrm{PhD}$ was from Universiti Putra Malaysia. He is currently an Associate Professor at UNITEN and heads the Center for Innovation and Design.Email: faristarlochan@gmail.com

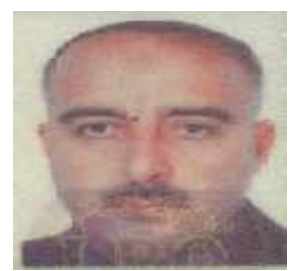

Hamad M. Hwas born in Iraq $\mathrm{He}$ obtained his Bachelors in Mechanical Engineering and Masters in Engineering from IRAQ. He is currently pursuing his $\mathrm{PhD}$ at UNITEN in the field of applied mechanics. 